\title{
Paddlefish buccal flow velocity during ram suspension feeding and ram ventilation
}

S. Laurie Sanderson

College of William and Mary, slsand@wm.edu

Joseph Cech Jr

A Y. Cheer

Follow this and additional works at: https://scholarworks.wm.edu/aspubs

Part of the Marine Biology Commons

\section{Recommended Citation}

Sanderson, S. Laurie; Cech, Joseph Jr; and Cheer, A Y., Paddlefish buccal flow velocity during ram suspension feeding and ram ventilation (1994). Journal of Experimental Biology, 186, 145-156.

https://scholarworks.wm.edu/aspubs/1040

This Article is brought to you for free and open access by the Arts and Sciences at W\&M ScholarWorks. It has been accepted for inclusion in Arts \& Sciences Articles by an authorized administrator of W\&M ScholarWorks. For more information, please contact scholarworks@wm.edu. 


\title{
PADDLEFISH BUCCAL FLOW VELOCITY DURING RAM SUSPENSION FEEDING AND RAM VENTILATION
}

\author{
S. LAURIE SANDERSON \\ Department of Biology, College of William and Mary, Williamsburg, VA 23187, USA \\ JOSEPH J. CECH, JR \\ Department of Wildlife and Fisheries Biology, University of California, Davis, \\ CA 95616, USA \\ AND A. Y. CHEER \\ Institute of Theoretical Dynamics, University of California, Davis, CA 95616, USA
}

Accepted 13 September 1993

\begin{abstract}
Summary
A micro-thermistor probe was inserted into the buccal cavity of freely swimming paddlefish to measure flow velocity during ram ventilation, ram suspension feeding and prey processing. Swimming speed was measured from videotapes recorded simultaneously with the buccal flow velocity measurements. Both swimming velocity and buccal flow velocity were significantly higher during suspension feeding than during ram ventilation. As the paddlefish shifted from ventilation to feeding, buccal flow velocity increased to approximately $60 \%$ of the swimming velocity. During prey processing, buccal flow velocity was significantly higher than the swimming velocity, indicating that prey processing involves the generation of suction. The Reynolds number $(R e)$ for flow at the level of the paddlefish gill rakers during feeding is about 30, an order of magnitude lower than the $R e$ calculated previously for pump suspension-feeding blackfish. These data, combined with data available from the literature, indicate that the gill rakers of ram suspension-feeding teleost fishes may operate at a substantially lower $R e$ than the rakers of pump suspension feeders.
\end{abstract}

\section{Introduction}

Suspension-feeding fish filter enormous quantities of water to extract minute prey that are too small to be sensed and engulfed as individual particles. Such species have been reported in at least 16 families belonging to 11 orders (Sanderson and Wassersug, 1993). These fish are either intermittent suction feeders ('pump' suspension feeders) that generate repetitive pulses of negative pressure to suck parcels of water containing prey into the buccal cavity, or continuous ram feeders ('tow-net' suspension feeders) that use forward body velocity to transport water through the mouth (Sanderson and Wassersug, 1990). Although the particle encounter mechanisms, rates and efficiencies of suspension

Key words: buccal flow, paddlefish, ram ventilation, suspension feeding, Polyodon spathula. 
feeding are dependent on the fluid dynamics at the level of the filtering elements (Shimeta and Jumars, 1991), a quantitative description of flow is available for only one pump suspension-feeding fish species (Sanderson et al. 1991; Sanderson and Cheer, 1993). Prior to the present study, flow velocities had not been measured inside the buccal cavities of any of the ram suspension-feeding species, which include many herring (Clupeidae), anchovies (Engraulidae) and mackerels (Scombridae) (Sanderson and Wassersug, 1993). Instantaneous flow velocities near the gills have rarely been measured directly during any fish behavior, including suction feeding and respiration (but see Holeton and Jones, 1975; Lauder, 1984).

We inserted a micro-thermistor flow probe into the buccal cavity of unrestrained paddlefish, Polyodon spathula Walbaum (Polyodontidae), to measure flow velocities during ram ventilation, ram suspension feeding and a post-feeding activity, which we refer to as 'prey processing'. By videotaping the fish in dorsal view, we recorded forward body velocities simultaneously with the buccal flow velocity measurements. Although swimming speeds have been quantified for many ram ventilators and ram suspension feeders, the extent to which buccal flow velocities differ from forward body velocity has not been investigated. Since flow through the buccal cavity could be affected by the extent of branchial arch and opercular abduction and the sizes of the gaps between gill rakers, the flow speed inside the buccal cavity could, in theory, be faster than, slower than, or equal to, the swimming velocity.

Buccal flow velocities are of interest for a number of reasons. (1) The flow velocity local to the filtering elements must be known to calculate the Reynolds number $(R e)$, a dimensionless index that is the ratio between inertial and viscous forces on the flow around the filtering structures. The Reynolds number provides qualitative insight into the physical character of the flow (Vogel, 1981). As the pattern of flow at the filtering structures changes with the magnitude of $R e$, particle encounter rates for the various filtration mechanisms are affected (Shimeta and Jumars, 1991). Retention efficiencies are also affected by $R e$ (Shimeta and Jumars, 1991). The only previous calculation of $R e$ for the filtering structures of a ram suspension-feeding fish used the swimming velocity (Friedland, 1985). (2) Since buccal flow velocity affects particle encounter rates, filter performance may be related directly to behaviors that induce changes in flow velocity, such as alterations of the distance between adjacent filter elements (Cheer and Koehl, 1987a,b; Imms, 1904) and the frequency of filter cleaning (Rubenstein and Koehl, 1977). Despite this relationship between flow velocity and filter performance, the variability of buccal flow velocities in ram suspension feeders has not been quantified. (3) Some ram suspension-feeding fish species can switch to a suspension-feeding behavior termed 'gulping' (e.g. Gibson and Ezzi, 1990; Janssen, 1976). Although the ecological conditions that trigger this switch have been investigated experimentally, the functional consequences have not been studied. For example, are comparable buccal flow velocities generated during the two feeding modes, and is buccal flow velocity related to prey size, concentration or mobility? (4) Experiments on Xenopus laevis tadpoles (Wassersug and Murphy, 1987; Feder et al. 1984) demonstrated that there is a functional conflict between suspension feeding and respiration. This tadpole species lacks gill filaments and uses the same buccopharyngeal surfaces for gas exchange and food particle retention. Although 
prey captured on fish gill rakers would be expected to alter the pattern of flow at the gill arches, data are not available to indicate how the flow velocity directly anterior to gill filaments during ram suspension feeding differs from that during ram ventilation. To test the hypothesis that there is a functional conflict between suspension feeding and respiration in fish, the flow quantification techniques that we have used could be combined in subsequent studies with an analysis of the relationship between filtration efficiency and oxygen extraction efficiency.

\section{Materials and methods}

\section{Experimental design}

Paddlefish were maintained in a circular tank (diameter $1.2 \mathrm{~m} \times 0.2 \mathrm{~m}$ deep) on a diet of Purina trout chow (floating pellets, $2.5 \mathrm{~mm}$ ) and dead adult brine shrimp (Artemia). In this flow-through system, water $\left(25^{\circ} \mathrm{C}\right)$ entering the tank established a clockwise current of $5-10 \mathrm{~cm} \mathrm{~s}^{-1}$ and then exited via a standpipe in the center of the tank. During training periods and experiments, the flow of incoming water was stopped. This procedure ensured that the flow velocity measured inside the buccal cavity was generated entirely by the activities of the fish. All specimens exhibited normal external morphology, with a straight rostrum and gill cover flaps that extended completely over the gill arches.

Flow records were obtained from two locations inside the buccal cavity of each of three specimens $(36-45 \mathrm{~cm}$ total length, $22-29 \mathrm{~cm}$ eye-to-fork length). Specimens were anesthetized with MS-222 $\left(200 \mathrm{mg}^{-1}\right)$ and placed in a shallow tray containing tank water with a lower dose of MS-222 $\left(67 \mathrm{mg} \mathrm{l}^{-1}\right)$ and a diffuser-stone attached to an oxygen cylinder. A polyethylene cannula ( $1.4 \mathrm{~mm}$ i.d., $1.9 \mathrm{~mm}$ o.d.) was implanted through a hole drilled in either the posteroventral ossified portion of the hyomandibula or the intertemporo-supratemporal bones of the skull roof, medial to the spiracle (Fig. 1; Grande and Bemis, 1991). The hyomandibular insertion site allowed the flow probe to be placed within $2 \mathrm{~mm}$ anterolateral to the gill rakers on ceratobranchial I during ram

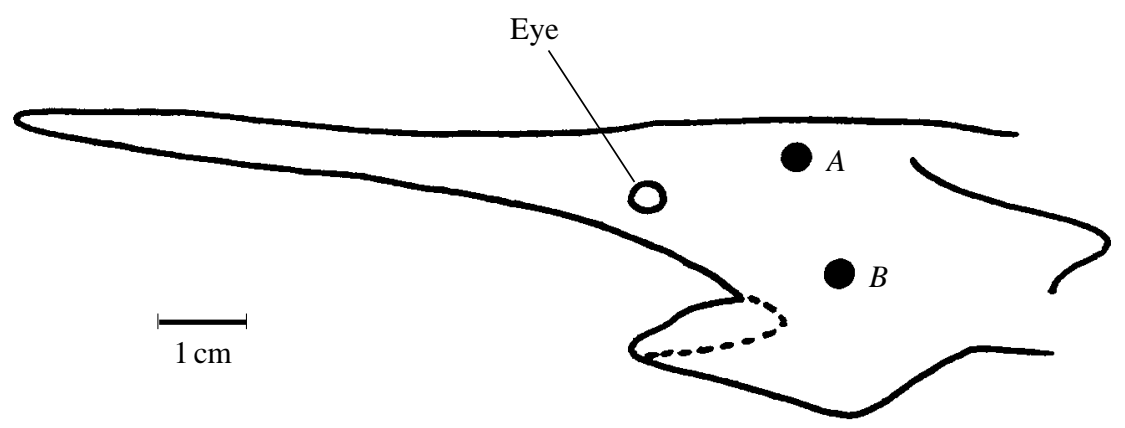

Fig. 1. Diagram of the head of a ram suspension-feeding paddlefish, showing where the flow probe was inserted into the buccal cavity. $(A)$ Insertion through intertemporo-supratemporal bones of the skull roof. $(B)$ Insertion through the posteroventral ossified portion of the hyomandibula. 
suspension feeding. At the neurocranial insertion site, the flow probe was positioned near the center of the oral roof, approximately $1.5 \mathrm{~cm}$ posterior to the mouth opening.

One end of the cannula was flanged so that it lay almost flush with the tissue lining the interior of the buccal cavity. Although we experimented with placing the cannula through the spiracle, we rejected this location because of concern that the pattern of flow inside the buccal cavity might be disrupted and because the cannula tended to tear the tissue around the spiracle. Externally, the cannula was threaded through a small piece of neoprene rubber to prevent it sliding further into the buccal cavity. By comparing videotapes of the fish taken prior to and following cannula implantation, we determined that the presence of the cannula did not affect swimming or feeding behavior. Data were collected within 1-2 days of cannula implantation; the cannula was then removed. Only one cannula was implanted in each fish at any given time, and the insertion sites were allowed to heal before a cannula was implanted at the second location.

To construct the flow probe, the leads from a glass bead thermistor $(1.09 \mathrm{~mm}$ diameter, Fenwal part no. 112-101BAJ-B01) were soldered to insulated wire (75 $\mu \mathrm{m}$ diameter, California Fine Wire Co., COA-101, H-ML). The circuit design was modified from that of LaBarbera and Vogel (1976). The probe was calibrated from 0 to $147 \mathrm{~cm} \mathrm{~s}^{-1}$ in a flume with a calibrated speed controller and was temperature-compensated from 20 to $30^{\circ} \mathrm{C}$. The $3 \mathrm{~dB}$ dropoff point occurred between 10 and $100 \mathrm{~Hz}$. Signals at frequencies up to $100 \mathrm{~Hz}$ were easily discernible.

During the experiments, the flow probe was threaded through the cannula until the entire length of the glass bead (approximately $1.5 \mathrm{~mm}$ ) protruded into the buccal cavity, as determined by a sudden increase in the velocity of the flow observed in real time with an oscilloscope. No measurable increase in flow velocity resulted from threading the probe farther into the buccal cavity. The output of the probe was sampled at $100 \mathrm{~Hz}$ by a GW Instruments MacADIOS 411 A/D convertor controlled by an Apple Macintosh Plus. Probe placement was verified in preliminary experiments by correlating the amplitude and pattern of the flow signal with a view of the probe's location obtained using a fiberoptic endoscope (Instrument Technology, Inc.) inserted behind the probe in the cannula.

Signals from the flow probe were recorded during ram ventilation, ram suspension feeding on dead adult brine shrimp (Artemia) and during an activity which we refer to as 'prey processing' that occurred after ram suspension feeding. A Panasonic WV-2170 video camera was suspended above the center of the tank to record the paddlefish at 30 frames s $^{-1}$ in dorsal view as they swam during the experiments. The videotape was begun synchronously with the recording of flow data from the buccal cavity.

\section{Calculation of Reynolds number}

The Reynolds number $(R e)$ is a dimensionless index that summarizes the relative importance of inertial (fluid momentum) forces and viscous (fluid stickiness) forces. The magnitude of $R e$ indicates the characteristics of the flow at the level of the filtering apparatus. The equation for $R e$ is:

$$
R e=(U L \rho) / \mu,
$$

where $U$ is the water velocity at the level of the filtering structures, $L$ is the characteristic 
length dimension of the filtering structures, $\rho$ is the density of the water and $\mu$ is the dynamic viscosity of the water. $R e$ provides insight into the processes of food particle capture at the filtering structures of suspension-feeding fishes (LaBarbera, 1984; Rubenstein and Koehl, 1977).

\section{Data processing and statistical analysis}

By referring to the videotapes, we identified segments of the buccal flow records during which the fish engaged solely in one of three activities: ram ventilation, ram suspension feeding or prey processing. A program written using GW Instruments MacADIOS Manager 411 software was used to determine the magnitude (in $\mathrm{cm} \mathrm{s}^{-1}$ ) of each peak in each segment of the flow record, and mean peak flow velocity was calculated for each segment (Sanderson et al. 1991). The mean value of all points in each segment was also calculated, to give a mean flow velocity $\left(\mathrm{cm} \mathrm{s}^{-1}\right)$ for the waveform.

The forward movement of the fish was traced from the video monitor onto acetate sheets. The tracings were digitized on a Houston Instruments HIPAD digitizing tablet. For each time period corresponding to an analyzed segment of the buccal flow records, the forward body velocity of the fish was calculated in $\mathrm{cm} \mathrm{s}^{-1}$.

A two-way model I analysis of variance (ANOVA) was used to assess whether mean peak flow velocities differed significantly between cannula locations (hyomandibula and neurocranium) and between activities (ram ventilation, ram suspension feeding and prey processing). A one-way ANOVA tested whether the three activities were associated with significantly different forward body velocities. Multiple pairwise comparisons of means were calculated for each factor that showed statistical significance. The equation used for these pairwise comparisons was:

$$
t^{*}=\left(\bar{Y}_{1}-\bar{Y}_{2}\right) /\left[\operatorname{MSE}\left(n_{1}^{-1}+n_{2}^{-1}\right)\right]^{1 / 2},
$$

where $\bar{Y}_{1}$ and $\bar{Y}_{2}$ are the mean values of the variables under comparison, MSE is the mean square error obtained from the ANOVA, and $n_{1}$ and $n_{2}$ are the sample sizes for $\bar{Y}_{1}$ and $\bar{Y}_{2}$ (Neter et al. 1985). The $P$ value corresponding to the test statistic ( $\left.t^{*}\right)$ was determined from a two-tailed table of critical values of Student's $t$-distribution (Miller, 1981), using the degrees of freedom for the mean square error. An experiment-wise type I error rate of $5.0 \%$ was applied using the sequential Bonferroni method (Rice, 1989). Using this sequential Bonferroni method, the probability of a type I error is less than or equal to an $\alpha$ value of 0.05 for the family consisting of all pairwise comparisons relating to the ANOVA (Rice, 1989). Statistical analyses were conducted using data pooled from the three fish.

Because forward body velocities were recorded simultaneously with buccal flow velocities, two-tailed paired $t$-tests were used to test for significant differences between these two sets of measurements.

\section{Results}

Flow patterns

During ram ventilation, the fish swam forward with their mouths slightly open. As the 


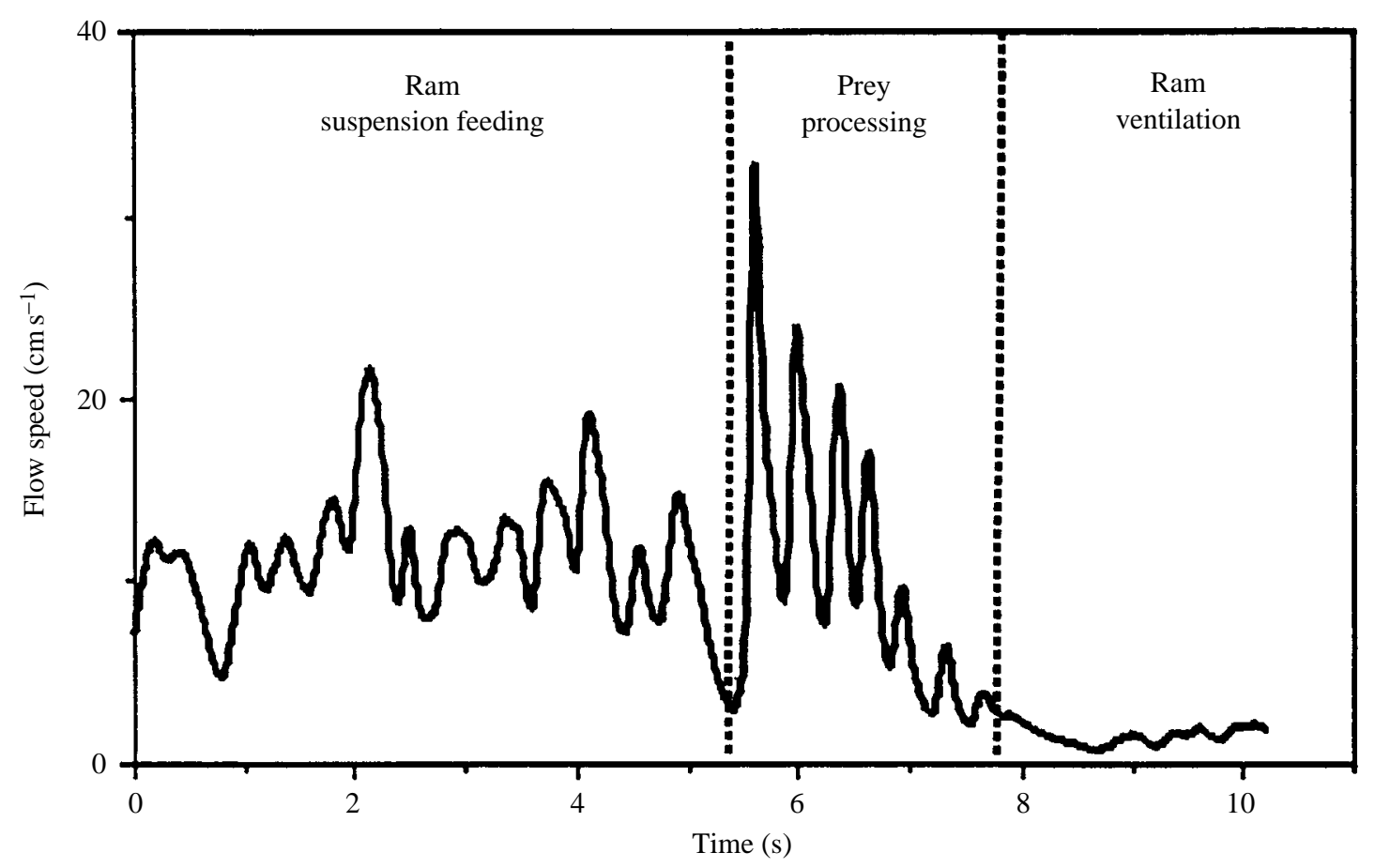

Fig. 2. Flow velocity sequence recorded from the hyomandibular cannula of a paddlefish during ram suspension feeding, prey processing and ram ventilation.

fish began ram suspension feeding, they opened their mouths wide. During prey processing, the fish repeatedly opened their mouths slightly and closed their mouths. Oral and opercular movements during prey processing were highly variable.

In the experiments, a bout of ram suspension feeding was typically followed by prey processing and a return to ram ventilation. Each of these three activities was characterized by a distinctive flow pattern (Fig. 2). The flow patterns recorded at the hyomandibular cannula, less than $2 \mathrm{~mm}$ anterolateral to the gill rakers on ceratobranchial I, were comparable to those recorded at the cannula implanted in the skull roof.

\section{Buccal flow velocity}

Fig. 3 illustrates the flow velocities recorded at the two cannula locations in one of the paddlefish during the three activities. Flow velocities recorded at the hyomandibular cannula were similar to those recorded at the neurocranial cannula. A two-way ANOVA confirmed that there was no significant difference between the mean peak flow velocities recorded at the two locations in the three specimens $(P>0.05$, Table 1$)$. The three activities were, however, associated with significantly different mean peak flow velocities $(P<0.0001$, Table 1). All three pairwise comparisons of means showed significant differences between the mean peak velocities for the three activities $(P \leqslant 0.05$, Table 2). 


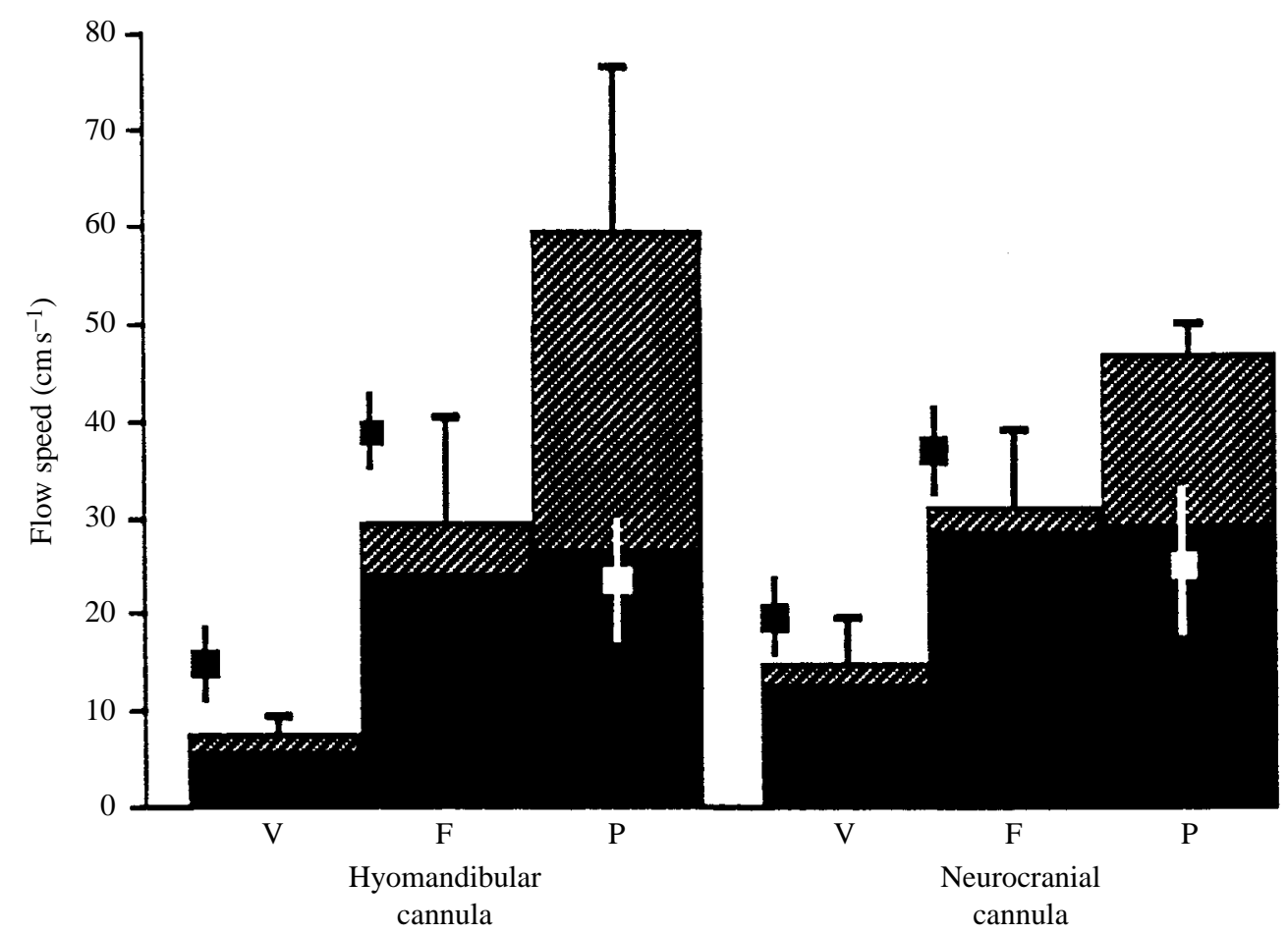

Fig. 3. Histogram of buccal flow velocities recorded at the two cannula locations in a paddlefish during ram ventilation $(\mathrm{V})$, ram suspension feeding $(\mathrm{F})$ and prey processing $(\mathrm{P})$. Hatched bars are mean peak flow velocity, filled bars are mean waveform velocity and error bars are 1 S.D. for the mean peak flow velocity. Squares show mean swimming velocity ( \pm S.D.) measured from the videotapes recorded simultaneously with the buccal flow velocities.

Table 1. Two-way ANOVA assessing the effects of activity (ram ventilation, ram suspension feeding and prey processing) and cannula location (hyomandibula and neurocranium) on buccal flow velocity

\begin{tabular}{lcrrrc}
\hline Source & $\begin{array}{c}\text { Degrees of } \\
\text { freedom }\end{array}$ & $\begin{array}{c}\text { Sum of } \\
\text { squares }\end{array}$ & $\begin{array}{c}\text { Mean } \\
\text { square }\end{array}$ & $F$ value & $P$ value \\
\hline Activity & 2 & 4840.0 & 2420.0 & 14.17 & $<0.0001$ \\
Cannula location & 1 & 520.6 & 520.6 & 3.05 & 0.087 \\
Interaction & 2 & 111.6 & 55.8 & 0.33 & 0.72 \\
Error & 49 & 8364.7 & 170.7 & & \\
\hline
\end{tabular}

\section{Swimming velocity}

The swimming velocities during the three activities were significantly different (oneway ANOVA; $F=24.9$; d.f. $=2,54 ; P<0.0001$ ). In a pairwise multiple means comparison test, the swimming velocities measured during ram ventilation were not significantly different from those during prey processing $(P>0.05$, Table 2$)$. However, during ram 
Table 2. Mean peak buccal flow velocities and mean swimming velocities recorded simultaneously during the three activities (cannula locations combined)

\begin{tabular}{lccc}
\hline & $\begin{array}{c}\text { Mean peak buccal } \\
\text { flow velocity } \\
\left(\mathrm{cm} \mathrm{s}^{-1}\right)\end{array}$ & $\begin{array}{c}\text { Mean forward } \\
\text { body velocity } \\
\left(\mathrm{cm} \mathrm{s}^{-1}\right)\end{array}$ & $\begin{array}{c}\text { Sample } \\
\text { size }\end{array}$ \\
\hline Ram ventilation & $7.6 \pm 1.9$ & $19.8 \pm 1.0$ & 10 \\
Ram suspension feeding & $19.3 \pm 1.7$ & $32.2 \pm 1.1$ & 36 \\
Prey processing & $38.4 \pm 8.1$ & $20.9 \pm 1.9$ & 9
\end{tabular}

Values are mean \pm S.E.

The buccal flow velocities for all possible pairs of activities were significantly different (multiple means comparison tests, $P \leqslant 0.05)$.

The swimming velocity during ram suspension feeding was significantly higher than the swimming velocities during ram ventilation and during prey processing (multiple means comparison tests, $P \leqslant 0.05)$.

suspension feeding, the fish increased their swimming velocities significantly above those measured for both ram ventilation and prey processing ( $P \leqslant 0.05$, Table 2$)$.

Paired $t$-tests, combining data recorded at the two cannula locations, compared the mean peak buccal flow velocities and the mean swimming velocities recorded simultaneously. During ram ventilation, buccal flow velocity $\left(7.6 \mathrm{~cm} \mathrm{~s}^{-1}\right)$ was less than $40 \%$ of the swimming velocity ( $\left.19.8 \mathrm{~cm} \mathrm{~s}^{-1} ; P=0.0005\right)$. During ram suspension feeding, buccal flow velocity $\left(19.3 \mathrm{~cm} \mathrm{~s}^{-1}\right)$ was approximately $60 \%$ of the swimming velocity (32.2 $\left.\mathrm{cm} \mathrm{s}^{-1} ; P<0.0001\right)$. However, during prey processing, buccal flow velocity $\left(38.4 \mathrm{~cm} \mathrm{~s}^{-1}\right)$ was significantly higher than the swimming velocity $\left(20.9 \mathrm{~cm} \mathrm{~s}^{-1} ; P=0.03\right)$.

\section{Discussion \\ Buccal flow velocity}

The mean peak flow velocities recorded during ram ventilation and ram suspension feeding were significantly lower than the mean swimming velocities recorded simultaneously (Fig. 3, Table 2). These differences are not due to boundary layer effects in the vicinity of the oral roof or gill rakers, since the flow velocity did not increase when the probe was inserted farther into the buccal cavity. There are two possible explanations for these differences between buccal flow velocity and swimming velocity. If resistance to flow inside the buccal cavity is high, water will pass through the buccal cavity at a speed that is slower than the forward body velocity of the fish. In this case, some of the water molecules that are on a trajectory into the mouth will be diverted around the fish's body. An alternative explanation is that the flow probe was recording from locations where the buccal cavity was wider than the gape of the mouth. According to the principle of continuity, as a pipe widens downstream, the flow velocity inside the pipe decreases (Vogel, 1981). To test these two hypotheses, dye streams could be used to visualize flow and silicone casts could be made of the buccal cavity.

The mean peak flow velocities recorded during prey processing were higher than the 
mean swimming velocities and were quite variable (Table 2), indicating that the paddlefish were generating negative pressure inside their buccal cavities. Although paddlefish can generate suction using a buccal pump for respiration at very slow swimming speeds (Burggren and Bemis, 1992), the use of suction during prey processing by paddlefish has not been reported previously. Paddlefish may also use suction during 'gulping' behavior (see Gibson and Ezzi, 1990; Janssen, 1976) directed at concentrations of prey (S. L. Sanderson, personal observation).

External observations made during prey processing suggest that the paddlefish is using water currents as a 'hydrodynamic tongue' to manipulate prey within the buccal cavity. Unfortunately, it is not known where the prey are located immediately prior to this processing phase. If prey are retained on the gill rakers, as Rosen and Hales (1981) have proposed, then processing may involve the use of suction to generate flow in both the anterior and posterior directions. Such flow may lift prey from the rakers and transport them to the esophagus. Processing movements similar to those in paddlefish have been observed in a number of intermittent suction and continuous ram suspension-feeding species (Sanderson et al. 1991; Ehlinger, 1989; Sibbing et al. 1986; S. L. Sanderson, personal observation). This deserves further study, as the transport of particles from the filter elements to the esophagus is one of the least understood aspects of suspension feeding in fish (Sanderson and Wassersug, 1993).

\section{Swimming velocity}

As the paddlefish shifted from ram ventilation to ram suspension feeding, they increased their swimming velocity and, consequently, increased their buccal flow velocities (Table 2). An increase in swimming speed during feeding has been reported for a number of other ram suspension-feeding fish species, including Cape anchovy (Engraulidae; James and Probyn, 1989), Atlantic mackerel (Scombridae; Pepin et al. 1988) and Atlantic menhaden (Clupeidae; Durbin et al. 1981). Durbin and Durbin (1983) experimentally derived energy and nitrogen budgets for Atlantic menhaden. They calculated that, as plankton concentration increased, the rate of energy intake increased per unit of energy expenditure. Consequently, the swimming speed during feeding that maximized growth rate also increased with increasing plankton concentration (particle size and abundance).

\section{Reynolds number}

We found that the mean peak buccal flow velocity at the rakers during ram suspension feeding in paddlefish (22-29 cm eye-to-fork length) was $19 \mathrm{~cm} \mathrm{~s}^{-1}$. According to the extensive morphometric data of Rosen and Hales (1981), the mean gill raker width in a paddlefish of $25 \mathrm{~cm}$ eye-to-fork length is approximately $0.015 \mathrm{~cm}$. Using these values, the $R e$ for flow at the level of the gill rakers is approximately 30 .

Given that $R e$ is the most important physical variable describing the interaction of fluids with solids over a range of sizes and flow speeds (Vogel, 1981), a comparison of $R e$ between ram and pump suspension-feeding species is of interest. By using a thermistor probe to record flow velocities at a number of locations inside the buccal cavities of unrestrained, pump suspension-feeding Sacramento blackfish (Cyprinidae, $32-33 \mathrm{~cm}$ 
standard length), Sanderson et al. (1991) documented that water directly anterior to the gill rakers travels at a peak velocity of $55-60 \mathrm{~cm} \mathrm{~s}^{-1}$, approximately three times higher than the velocity recorded in paddlefish. The gill raker width in these blackfish was approximately $0.05 \mathrm{~cm}$, three times the width of the rakers in paddlefish of a comparable body length. Using these values to calculate $R e$ for flow at the level of blackfish rakers leads to an $R e$ of about 300, an order of magnitude higher than that calculated for paddlefish. Flow velocity measurements at the level of the gill rakers, necessary for the calculation of $R e$, are not available for other pump suspension-feeding species. However, Hoogenboezem et al. (1991) indirectly measured the flow velocity in the buccal cavities of pump suspension-feeding bream (Cyprinidae) using X-ray cinematography to track the movement of zooplankters that had a $1.0 \mathrm{~mm}$ diameter iron sphere glued to their carapace. Anterior to the gill arches, the flow velocity was $114.9 \pm 62.8 \mathrm{~cm} \mathrm{~s}^{-1}$ (mean \pm S.D., $N=25$ ). This figure is comparable to the flow velocities recorded $1 \mathrm{~cm}$ inside the blackfish buccal cavity during feeding (118-141 $\mathrm{cm} \mathrm{s}^{-1}$, Sanderson et al. 1991). Re is also dependent on the size of the gill rakers. A review of the literature indicates that raker widths for four pump suspension-feeding teleost species $(5.8-37.4 \mathrm{~cm}$ standard length) other than blackfish range from approximately $0.008-0.03 \mathrm{~cm}$ (S. L. Sanderson, in preparation).

Data necessary for the calculation of $R e$ in other ram suspension-feeding species are limited. Friedland (1985) used a probable forward body velocity of Atlantic menhaden ( $15 \mathrm{~cm}$ fork length, $22.5-37.5 \mathrm{~cm} \mathrm{~s}^{-1}$ ) and the width of the smallest unit in the branchial apparatus (the branchiospinule, $0.001 \mathrm{~cm}$ ) to calculate an $R e$ of 2-3. Although Friedland (1985) hypothesized that the branchiospinule is the filtering structure in menhaden, the actual site of filtration has not been established. Substituting the gill raker width for the branchiospinule width results in an $R e$ of 8-12. A review of the literature indicates that forward body velocities during feeding for five ram suspension-feeding teleost species (8-27.9 $\mathrm{cm}$ length) range from approximately 11 to $42.7 \mathrm{~cm} \mathrm{~s}^{-1}$, and gill raker widths for three such species $(13.6-20.0 \mathrm{~cm}$ length) range from 0.002 to $0.007 \mathrm{~cm}$ (S. L. Sanderson, in preparation). If, as in paddlefish, peak flow velocity at the gill rakers of such species is roughly $60 \%$ of swimming velocity, the gill rakers of ram suspension feeders may, in general, operate at a substantially lower $R e$ than the rakers of pump suspension feeders.

Assessing the biological significance of such a difference in $R e$ will require additional empirical and mathematical studies. Shimeta and Jumars (1991) pointed out that the streamline patterns around circular cylinders at intermediate $R e$ values from 10 to 40 are qualitatively different from those at $R e$ values below 10 and $R e$ values above 40 . Their model suggests that the particle encounter rate due to direct interception increases nonlinearly as $R e$ increases from approximately 1 to 40 . Above an $R e$ of approximately 40, vortex shedding might reduce particle retention efficiency (Shimeta and Jumars, 1991).

This potential reduction of particle retention efficiency at the gill rakers of pump suspension-feeding species with $R e$ values greater than 40 is of interest because Sanderson et al. (1991) found that the gill rakers are not the site of particle capture in pump suspension-feeding blackfish. Blackfish gill rakers act as barriers to fluid flow rather than as filtering elements. Particle-laden water is guided along the faces of the gill rakers to the mucus-covered roof of the oral cavity, where particles are retained. In addition, experiments by Drenner et al. (1987) indicated that the gill rakers of pump 
suspension-feeding tilapia (Cichlidae) are not the site of particle capture. Surgical removal of tilapia rakers did not affect particle ingestion rates or size selectivity.

More information is needed on the sites and mechanisms of particle retention in pump and ram suspension-feeding species. Additional studies with a thermistor flow probe and fiberoptic endoscope could test the hypothesis that higher buccal flow velocities, larger gill rakers and particle entrapment on buccal surfaces other than gill rakers (e.g. oral roof or gill arches) are found in pump suspension-feeding species, whereas lower buccal flow velocities and particle retention on fine, comblike gill rakers are associated with ram suspension feeding. To determine the factors that constrain a teleost fish species to one mode of suspension feeding, we will need to identify the filtering structures, to investigate how their morphology affects particle encounter and retention and to characterize the pattern of flow in their vicinity. We have initiated research in this area by providing data which indicate that the flow velocities through the buccal cavities of ram suspensionfeeding fishes, and hence the Reynolds numbers at the level of the filtering structures, may be substantially lower than those in pump suspension-feeding fishes.

This study was supported by an NSF Postdoctoral Research Fellowship in Environmental Biology (BSR-8800190) and a University of California President's Fellowship to S.L.S., a University of California Agricultural Experiment Station grant to J.J.C. (no. 3455-H) and NSF OCE-9019115 to A.Y.C.. We thank M. Patterson for electronics expertise; D. Erickson and J. Dykes for statistical consultations and data analysis; K. Kroll, J. VanEnnenam and S. Doroshov for use of their paddlefish; P. Lutes for accommodating us at the Aquatic Center, Aquaculture and Fisheries Program, UC Davis; and S. Sharpe, B. Meese, P. Young, T. Hopkins, M. Choi and D. Castleberry for advice and assistance.

\section{References}

BurgGren, W. W. AND Bemis, W. E. (1992). Metabolism and ram gill ventilation in juvenile paddlefish, Polyodon spathula (Chondrostei: Polyodontidae). Physiol. Zool. 65, 515-539.

Cheer, A. Y. L. And Koehl, M. A. R. (1987a). Paddles and rakes: fluid flow through bristled appendages of small organisms. J. theor. Biol. 129, 17-39.

CheER, A. Y. L. AND KoEHL, M. A. R. (1987b). Fluid flow through filtering appendages of insects. IMA J. Math. appl. Med. Biol. 4, 185-199.

Drenner, R. W., Vinyard, G. L., Hambright, K. D. and Gophen, M. (1987). Particle ingestion by Tilapia galilaea is not affected by removal of gill rakers and microbranchiospines. Trans. Am. Fish. Soc. 116, 272-276.

Durbin, A. G., Durbin, E. G., Verity, P. G. And Smayda, T. J. (1981). Voluntary swimming speeds and respiration rates of a filter-feeding planktivore, the Atlantic menhaden, Brevoortia tyrannus (Pisces: Clupeidae). Fishery Bull. Fish Wildl. Serv. U.S. 78, 877-886.

Durbin, E. G. AND Durbin, A. G. (1983). Energy and nitrogen budgets for the Atlantic menhaden, Brevoortia tyrannus (Pisces: Clupeidae), a filter-feeding planktivore. Fishery Bull. Fish Wildl. Serv. U.S. 81, 177-199.

EHLINGER, T. J. (1989). Foraging mode switches in the golden shiner (Notemigonus crysoleucas). Can. J. Fish. aquat. Sci. 46, 1250-1254.

Feder, M. E., Seale, D., Boraas, M. E., Wassersug, R. J. and Gibbs, A. G. (1984). Functional conflicts between feeding and gas exchange in suspension-feeding tadpoles, Xenopus laevis. J. exp. Biol. 110, 91-98.

FRIEDLAND, K. D. (1985). Functional morphology of the branchial basket structures associated 
with feeding in the Atlantic menhaden, Brevoortia tyrannus (Pisces: Clupeidae). Copeia 1985, $1018-1027$.

GiBSON, R. N. AND EzZI, I. A. (1990). Relative importance of prey size and concentration in determining the feeding behaviour of the herring Clupea harengus. Mar. Biol. 107, 357-362.

GRANDE, L. AND BEMIS, W. E. (1991). Osteology and phylogenetic relationships of fossil and Recent paddlefishes (Polyodontidae) with comments on the interrelationships of Acipenseriformes. J. Vert. Paleon. 11 (suppl. to no. 1), 1-121.

Holeton, G. F. AND JonEs, D. R. (1975). Water flow dynamics in the respiratory tract of the carp (Cyprinus carpio L.). J. exp. Biol. 63, 537-549.

Hoogenboezem, W., van den Boogaart, J. G. M., Sibbing, F. A., Lammens, E. H. R. R., Terlouw, A. AND OsSE, J. W. M. (1991). A new model of particle retention and branchial sieve adjustment in filterfeeding bream (Abramis brama, Cyprinidae). Can. J. Fish. aquat. Sci. 48, 7-18.

ImMs, A. D. (1904). Notes on the gill-rakers of the spoonbill sturgeon, Polyodon spathula. Proc. zool. Soc., Lond. 2, 22-35.

JAMES, A. G. AND PROBYn, T. (1989). The relationship between respiration rate, swimming speed and feeding behaviour in the Cape anchovy Engraulis capensis Gilchrist. Mar. Ecol. Prog. Ser. 50, 275-294.

JANSSEN, J. (1976). Feeding modes and prey size selection in the alewife (Alosa pseudoharengus). J. Fish. Res. Bd Can. 33, 1972-1975.

LABARBERA, M. (1984). Feeding currents and particle capture mechanisms in suspension feeding animals. Am. Zool. 24, 71-84.

LABARbera, M. AND Vogel, S. (1976). An inexpensive thermistor flowmeter for aquatic biology. Limnol. Oceanogr. 21, 750-756.

LAUDER, G. V. (1984). Pressure and water flow patterns in the respiratory tract of the bass (Micropterus salmoides). J. exp. Biol. 113, 151-164.

MiLler, R. G., JR (1981). Simultaneous Statistical Inference, 2nd edn. New York: Springer-Verlag.

Neter, J., Wasserman, W. and Kutner, M. H. (1985). Applied Linear Statistical Models, 2nd edn. Homewood, IL: Irwin, Inc.

Pepin, P., Koslow, J. A. ANd Pearre, S., JR (1988). Laboratory study of foraging by Atlantic mackerel, Scomber scombrus, on natural zooplankton assemblages. Can. J. Fish. aquat. Sci. 45, 879-887.

Rice, W. R. (1989). Analyzing tables of statistical tests. Evol. 43, 223-225.

Rosen, R. A. And Hales, D. C. (1981). Feeding of paddlefish, Polyodon spathula. Copeia 1981, $441-455$.

Rubenstein, D. I. AND KoeHL, M. A. R. (1977). The mechanisms of filter feeding: some theoretical considerations. Am. Nat. 111, 981-994.

Sanderson, S. L., Cech, J. J., Jr and Patterson, M. R. (1991). Fluid dynamics in suspension-feeding blackfish. Science 251, 1346-1348.

SANDERSON, S. L. AND CHEER, A. Y. (1993). Fish as filters: an empirical and mathematical analysis. In Fluid Dynamics in Biology, Contemporary Mathematics, vol. 141 (ed. A. Y. Cheer and C. P. van Dam), pp. 135-160. Providence: American Mathematical Society.

SANDERSON, S. L. AND WASSERSUG, R. (1990). Suspension-feeding vertebrates. Scient. Am. 262, 96-101.

SANDERSON, S. L. AND WASSERSUG, R. (1993). Convergent and alternative designs for vertebrate suspension feeding. In The Skull, vol. 3, Functional and Evolutionary Mechanisms (ed. J. Hanken and B. K. Hall), pp. 37-112. Chicago: The University of Chicago Press.

ShimetA, J. AND JumARS, P. A. (1991). Physical mechanisms and rates of particle capture by suspensionfeeders. Ocean. mar. Biol. A. Rev. 29, 191-257.

SibBing, F. A., OsSE, J. W. M. AND Terlouw, A. (1986). Food handling in the carp (Cyprinus carpio): its movement patterns, mechanisms and limitations. J. Zool., Lond. A 210, 161-203.

Vogel, S. (1981). Life in Moving Fluids: The Physical Biology of Flow. Boston: Willard Grant Press.

Wassersug, R. J. AND MurPhy, A. M. (1987). Aerial respiration facilitates growth in suspensionfeeding anuran larvae (Xenopus laevis). Exp. Biol. 46, 141-147. 